\title{
Abrasion Resistance of Two Dental Glass Ionomer Cement Materials after Radiant Heat Treatment
}

\author{
Dimitrios Dionysopoulos, Kosmas Tolidis, Thrasyvoulos Sfeikos, \\ Christina Karanasiou, and Xanthippi Parisi
}

Department of Operative Dentistry, School of Dentistry, Aristotle University of Thessaloniki, 54124 Thessaloniki, Greece

Correspondence should be addressed to Dimitrios Dionysopoulos; ddiondent@gmail.com

Received 31 March 2017; Revised 5 July 2017; Accepted 17 July 2017; Published 17 August 2017

Academic Editor: Fernando Lusquiños

Copyright (c) 2017 Dimitrios Dionysopoulos et al. This is an open access article distributed under the Creative Commons Attribution License, which permits unrestricted use, distribution, and reproduction in any medium, provided the original work is properly cited.

\begin{abstract}
The aim of this study was to evaluate the effect of a radiant heat treatment using a dental LED unit on the surface microhardness and abrasion resistance after toothbrushing simulation of two conventional GIC materials. Two conventional GIC materials were studied in this investigation: Ketac Fil Plus Aplicap and IonoStar Molar. Twenty disk-shaped specimens $(n=10)$ were prepared of each GIC $(7 \mathrm{~mm} \times 2 \mathrm{~mm})$ using cylindrical Teflon molds. Group 1 specimens were left in the mold to set without any treatment, while in Group 2 after placement in the mold the specimens were irradiated for $60 \mathrm{sec}$ at the top surface using a LED light-curing unit. Toothbrushing simulation was carried out using a commercial electric toothbrush which was fixed in a constructed device that allowed the heads of the brushes to be aligned parallel to the surface of the specimens and to control the pressure, with the following parameters: load of the toothbrush standardized at $250 \mathrm{~g}$, medium hardness toothbrush head, and rotation sense changing every $30 \mathrm{sec}$. The toothbrush abrasion test mechanism, based on a $1.25-\mathrm{Hz}$ frequency for 10,000 cycles, was equivalent to 800 days $(\sim 2$ years) of brushing. Surface hardness, surface roughness, and surface loss after abrasive procedure were evaluated using Vickers method and Vertical Scanning Interferometry. Data were statistically analyzed using one-way ANOVA and Tukey's post hoc test $(a=0.05)$. The radiant heat treatment increased the surface microhardness and decreased surface roughness and surface loss after abrasive procedures of both the tested GIC materials but to different extent. Between the tested GIC materials there were significant differences in their tested properties $(p<0.05)$.
\end{abstract}

\section{Introduction}

Glass ionomer cement (GIC) materials are commonly used in restorative dentistry and especially in patients with high caries risk such as children mainly due to their fluoride releasing and recharging abilities $[1,2]$, which provide inhibition of demineralization and enhancement of remineralization of adjacent tooth tissues during acidic attack [3]. In addition, other beneficial properties are their chemical adhesion [4] and good biocompatibility [5] to tooth tissues. In contrast, GIC materials present lower physical and mechanical properties compared to composite restorative materials. The most important disadvantage of GIC materials is their sensitivity to water contamination during the first stage of the setting reaction of GIC materials resulting in a soft, porous, and fragile cement surface vulnerable to cracks formation. This leads to lower surface hardness of the restoration and to decrease in wear resistance [6].

Setting reaction of GIC materials is an acid-base reaction between basic glasses, which are typically fluoroaluminosilicates and an aqueous solution of polyalkenoic acids, such as polyacrylic acid [7]. After mixing of the two components (powder-liquid) of GIC and as the setting reaction is continuous, an increase occurs in surface hardness which reaches the highest value when the reaction is complete [8]. The final surface hardness of a dental restoration is crucial for its resistance to wear (i.e., abrasion due to toothbrushing).

In previous studies various techniques have been suggested in order to increase the surface hardness of the GIC 
TABLE 1: The technical characteristics of the tested glass ionomer cements.

\begin{tabular}{lcccc}
\hline Material & Category & Manufacturer & Shade & Composition \\
\hline Ketac Fil Plus Aplicap & $\begin{array}{c}\text { Conventional } \\
\text { GIC } \\
\text { (capsules) }\end{array}$ & $\begin{array}{c}\text { 3M ESPE, } \\
\text { Seefeld, } \\
\text { Germany }\end{array}$ & A2 & $\begin{array}{c}\text { Powder: codium-strontium-aluminum- } \\
\text { lanthanum-fluorophosphosilicate glass } \\
\text { and pigments }\end{array}$ \\
\hline IonoStar Molar & $\begin{array}{c}\text { Conventional } \\
\text { GIC } \\
\text { (capsules) }\end{array}$ & $\begin{array}{c}\text { Voco GmbH, } \\
\text { Cuxhaven, } \\
\text { Germany }\end{array}$ & A2 & $\begin{array}{c}\text { Liquid: water, copolymer of acrylic } \\
\text { acid-maleic acid, tartaric acid }\end{array}$ \\
\hline
\end{tabular}

materials, which include radiant heat transfer by use of dental light-curing units such as light emitting diodes (LEDs) [911] or lasers [12], ultrasonic energy transfer to enhance the motivation and interaction of the reacted components of the GIC $[9,13,14]$, and application of calcium chloride $\left(\mathrm{CaCl}_{2}\right)$ solutions in order to enhance the acid-base reaction between carboxylate groups $\left(-\mathrm{COO}^{-}\right)$of the polyalkenoic acids and calcium cations $\left(\mathrm{Ca}^{+2}\right)$ of the glass particles of the cement $[15,16]$. Among the above techniques the most common one for improving the physical and mechanical properties of the GIC materials is the radiant heat treatment using dental LED curing units. Although many studies in the past investigated the effect of radiant heat treatments on the surface of GIC materials, the resistance in toothbrushing abrasion has never been evaluated before, and as a result this data is the novelty of the present investigation.

Therefore, the aim of this in vitro study was to evaluate the effect of a radiant heat treatment using a dental LED unit on the surface microhardness and abrasion resistance after toothbrushing simulation of two dental conventional GIC materials. Moreover, the correlation between surface microhardness and abrasion resistance was also evaluated. Three null hypotheses were formulated prior to the study: the first null hypothesis $\left(\mathrm{H}_{0} 1\right)$ was that the radiant heat treatment did not influence the surface microhardness of the tested GIC materials, the second null hypothesis $\left(\mathrm{H}_{0} 2\right)$ was that the radiant heat treatment did not affect the surface roughness of the tested GIC materials after the abrasive procedure, and the third null hypothesis $\left(\mathrm{H}_{0} 3\right)$ was that the radiant heat treatment did not influence the surface loss of the tested GIC materials after the abrasive procedure.

\section{Materials and Methods}

2.1. Preparation of the Specimens. Two conventional GIC materials were studied in this investigation; Ketac Fil Plus Aplicap (KF) and IonoStar Molar (IM). The technical characteristics of the GIC materials are shown in Table 1. Twenty disk-shaped specimens $(7 \mathrm{~mm}$ in diameter and $2 \mathrm{~mm}$ in thickness) were prepared of each tested GIC using cylindrical Teflon molds in room temperature $\left(23 \pm 1^{\circ} \mathrm{C}\right)$. The capsule of the glass ionomer material was activated and placed in a rotating mixer (RotoMix ${ }^{\mathrm{TM}}, 3 \mathrm{M}$ ESPE, Seefeld, Germany) for the recommended time $(10 \mathrm{sec})$. The mixed capsule was then loaded into a gun and immediately the cement was injected into the mold. Prior to material's placement, a polyester strip
(0.05 $\mathrm{mm}$ in thickness) was placed on a glass slab and the mold was then placed and the cement packed. Instantly, after filling the mold with the material, a second polyester strip was placed on top of the mold and a second glass slab was clamped in order to produce a standardized surface finishing and to remove the excess of the cement. The material was left to be cured for $5 \mathrm{~min}$ and then was removed from the mold and the cement excess that extruded around the edge of the mold was carefully removed by using a surgical blade. Subsequently, the surface of the specimen was observed by means of an optical microscope ( $\times 10$ magnification) to ensure that there were no air bubbles, cracks, or other deficiencies.

2.2. Experimental Groups. In this investigation there were two experimental groups $(n=10)$ for each GIC. In Group 1 , which was the control group of the study, the specimens after mixing were left in the mold to set without any treatment as described previously. In Group 2, after placement in the mold the specimens were irradiated for $60 \mathrm{sec}$ at the top surface using a dental LED light-curing unit (Valo, Ultradent, South Jordan, UT, USA) operating at $1400 \mathrm{~mW} / \mathrm{cm}^{2}$ with standard curing mode and wavelength range 395-480 nm. The energy density received on the surface of each specimen was $84 \mathrm{~J} / \mathrm{cm}^{2}$. A radiometer (Demetron LED Radiometer, Kerr Corp., Orange, CA, USA) was used to verify the output irradiance of the LED device. The diameter of the light tip was $10 \mathrm{~mm}$ and was constantly in contact with the polyester strip of the top surface of the specimen during irradiation. The highest temperature $(n=5)$ at the tip of the LED device during $60 \mathrm{sec}$ of irradiation was recorded by using a digital $\mathrm{K}$ type thermocouple (accuracy: $\pm 0.1^{\circ} \mathrm{C}$ ) and was $52.4 \pm 0.8^{\circ} \mathrm{C}$.

2.3. Surface Hardness Measurements. Surface hardness of the glass ionomer specimens was evaluated using Vickers method with a hardness tester (HMV-2000, Shimadzu, Tokyo, Japan) at a load of $200 \mathrm{~g}$ with an indentation time of $10 \mathrm{sec}$ (Vickers pyramid: diamond right pyramid with a square base and an angle of $a=136^{\circ}$ between the opposite faces at the vertex). After preparation of the specimens, they were immersed individually in $10 \mathrm{ml}$ artificial saliva in plastic containers and stored at $37 \pm 1^{\circ} \mathrm{C}$. The composition of artificial saliva was as follows: $0.103 \mathrm{~g} / \mathrm{l}$ of $\mathrm{CaCl}_{2}, 0.019 \mathrm{~g} / 1 \mathrm{MgCl}_{2} * 6 \mathrm{H}_{2} \mathrm{O}, 0.544 \mathrm{~g} / \mathrm{L}$ $\mathrm{KH}_{2} \mathrm{PO}_{4}$, and $2.24 \mathrm{~g} / \mathrm{l} \mathrm{KCl}$ and buffer (TCP-KOH) was added to adjust the $\mathrm{pH}$ to 7 [17]. Measurements of surface hardness were carried out after $24 \mathrm{~h}$. Five indentations were made on top surfaces of each glass ionomer specimen, one in the center 


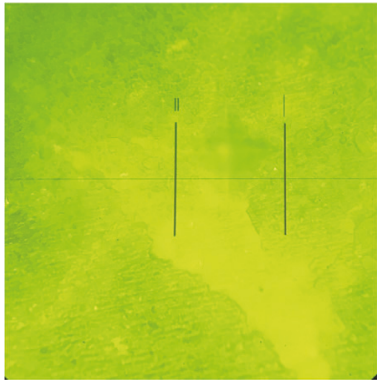

(a)

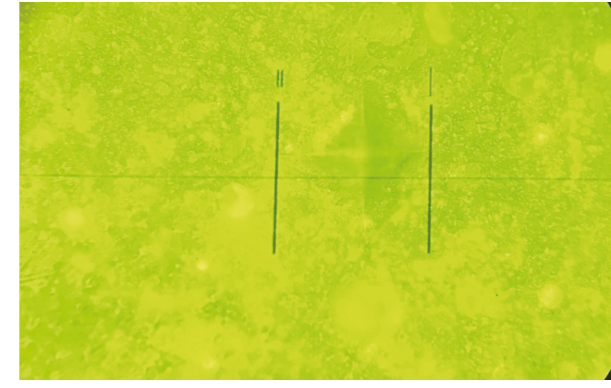

(b)

Figure 1: Representative images ( $\times 40$ magnification) of the Vickers hardness indentations on the surfaces of the tested glass ionomer cement materials. (a) Ketac Fill Plus Aplicap. (b) IonoStar Molar.

of the surface and one in every quadrant (at least $100 \mu \mathrm{m}$ from each other). The dimensions of the indentations were evaluated using the optical microscope of the hardness tester and the data were independently averaged and reported in Vickers Hardness Numbers (VHN). All the measurements of the testing were performed by two different researchers who did not know which experimental group was tested.

2.4. Procedure of Abrasion. A commercial electric toothbrush was used in this investigation (Oral- $\mathrm{B}^{\circledR}$, Braun, France) with the following parameters: load of the toothbrush standardized at $250 \mathrm{~g}$, medium hardness toothbrush head, and rotation sense changing every $30 \mathrm{sec}$. The electric toothbrush was fixed in a constructed device that allowed the heads of the brushes to be aligned parallel to the surface of the specimens and to control the pressure by an electric system. Before the abrasive procedure, half of each surface of the specimens was covered with one-sided adhesive tape (Wonder ${ }^{\circledR}$ Tape, P.V.C. Electrical Tape). In order to maintain the reference surfaces for lesion-depth determination and allow the exact superimposition of the baseline and posttreatment profiles, a groove was marked as a guide on the specimens at the limit with the adhesive tape. The toothbrush head was in direct contact with the specimen and $0.2 \mathrm{~g}$ of toothpaste (Colgate ${ }^{\circledR}$ Maximum Protection Caries plus Sugar Acid Neutralizer ${ }^{\mathrm{TM}}$, Colgate-Palmolive Company, UK) was weighted on a high precision scale, diluted in $500 \mu \mathrm{L}$ of distilled water, and applied directly on the surface of the specimen with a syringe. In this study, it was assumed that individuals brush their teeth twice a day for an average of $2 \mathrm{~min}$. There were a total of four quadrants with three surfaces of teeth to be brushed. As a toothbrush length covers approximately two or three teeth at the same time, each quadrant is brushed in two parts. Then, it is reasonable to assume that a 10-sec abrasion on each tooth surface effectively represent one person's daily tooth brushing habits. The toothbrush abrasion test mechanism, based on a $1.25-\mathrm{Hz}$ frequency for 10,000 cycles, was equivalent to $8000 \mathrm{sec}$ of abrasion. According to this data, 10,000 cycles was calculated to be equivalent to 800 days ( 2 years) of brushing.
2.5. Measurements of Surface Loss and Roughness Analysis. Measurements were done using a Vertical Scanning Interference (VSI) microscope (Bruker, ContourGT, Berlin, Germany) after abrasion procedures. During the experimental period the GIC specimens were stored in artificial saliva at $37 \pm 1^{\circ} \mathrm{C}$. VSI is based on light interferometry and operates as a noncontact optical profiler in vertical scanning mode to produce 3D topography maps of the sample surface. After removal of the adhesive tape for each half specimen, four images were obtained in the specimen's surface. The software Vision $64^{\mathrm{TM}}$ was used to acquire the data and compute the mean surface roughness ( $R \mathrm{a}$, expressed in $\mu \mathrm{m})$ on each image. For each half specimen, the values were averaged and the mean values were obtained. The enamel surface loss was calculated after superimposing the baseline and posttreatment profiles. The depth of the treated area for each specimen was calculated based on the subtraction of the two profiles.

2.6. Statistical Analysis. The data were statistically analyzed using SPSS Statistics 20.0 software (IBM Corp, Chicago, IL, USA). Surface hardness, surface roughness, and surface loss data of the glass ionomer specimens were statistically analyzed using one-way ANOVA and Tukey's post hoc test was used to detect statistical differences at a level of significance $a=0.05$. Kolmogorov-Smirnov test was applied to verify if the data were normally distributed. The relationship between surface microhardness (VHN) and surface loss $(\mu \mathrm{m})$ of the tested materials was defined by linear regression.

\section{Results}

3.1. Surface Microhardness. Means and standard deviations (VHN) of surface microhardness of the experimental groups of the study are shown in Table 2. Representative images ( $\times 40$ magnification) of the Vickers hardness indentations are illustrated in Figures 1(a) and 1(b). Radiant heat groups exhibited significant higher surface microhardness compared to control groups $(p<0.05)$. More specifically, KF specimens presented a $37.8 \%$ increase in surface microhardness, while 


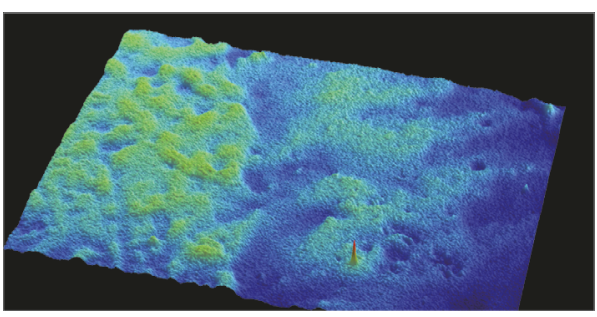

(a)

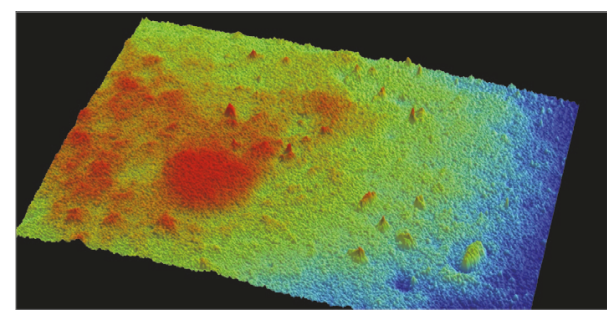

(b)

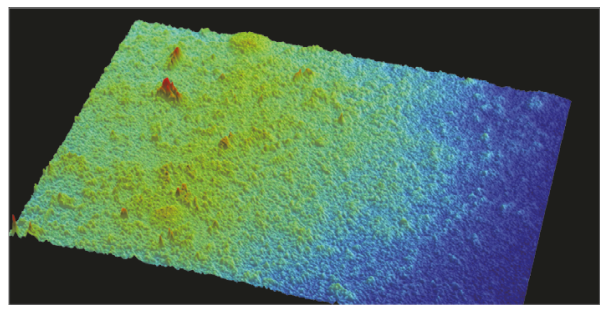

(c)

FIGURE 2: Representative topographic surface maps and surface analysis $(0.317 \times 0.238 \mathrm{~mm})$ of the Ketac Fil Plus Aplicap specimens (magnification $\times 20$ ). (a) Baseline, (b) abrasive surface (control group), and (c) abrasive surface (radiant heat group).

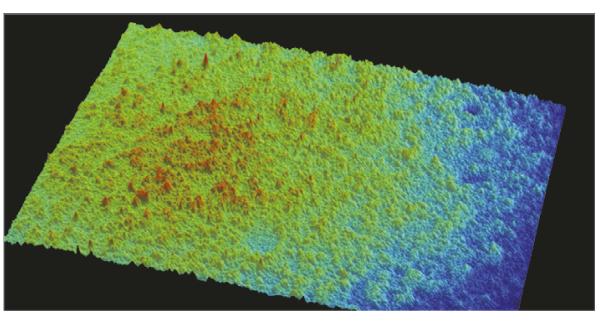

(a)

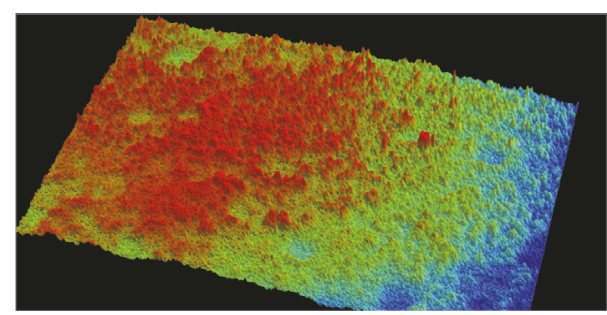

(b)

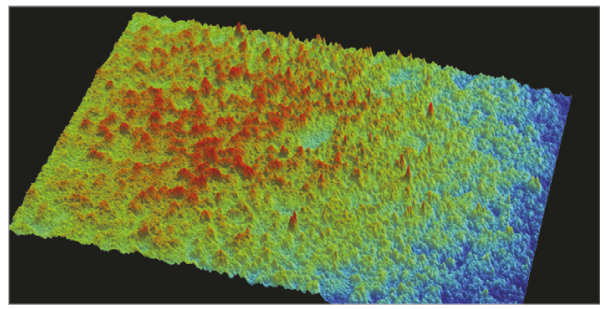

(c)

FIGURE 3: Representative topographic surface maps and surface analysis $(0.317 \times 0.238 \mathrm{~mm})$ of the IonoStar Molar specimens (magnification $\times 20$ ). (a) Baseline, (b) abrasive surface (control group), and (c) abrasive surface (radiant heat group).

TABLE 2: Mean values and standard deviations of surface hardness $(\mathrm{VHN})$ of the experimental groups of the study $24 \mathrm{~h}$ after preparation of the specimens. The same uppercase superscripts in columns indicate no significant differences between materials $(p>0.05)$. The same lowercase superscripts indicate no significant differences between treatments $(p>0.05)$.

\begin{tabular}{lccc}
\hline Material & Control & Radiant heat & \% increase \\
\hline Ketac Fil Plus Aplicap & $30.49 \pm 3.30^{\mathrm{Aa}}$ & $49.01 \pm 5.48^{\mathrm{Ab}}$ & $37.8 \%$ \\
IonoStar Molar & $30.72 \pm 2.87^{\mathrm{Aa}}$ & $38.24 \pm 5.82^{\mathrm{Bb}}$ & $19.7 \%$ \\
\hline
\end{tabular}

IM presented lower but significant increase (19.7\%). Between the tested GIC materials, although the surface microhardness of their control groups did not differ significantly $(p>0.05)$, the radiant heat group of KF exhibited significantly higher microhardness values $(p<0.05)$.

3.2. Surface Roughness. Means and standard deviations (Ra, $\mu \mathrm{m})$ of surface roughness of the covered and uncovered surfaces of the specimens of the experimental groups of the study after abrasion procedure are presented in Table 3. Representative topographic surface maps ( $\times 20$ magnification) and surface analysis of the tested specimens for $\mathrm{KF}$ are illustrated in Figures 2(a)-2(c) and for IM in Figures $3(a)-3(c)$. Surface roughness of the abrasive surfaces of the specimens was significantly higher compared to baseline 
TABLE 3: Mean values and standard deviations of surface roughness $(R \mathrm{a}, \mu \mathrm{m})$ of the covered and uncovered surface of the specimens of the experimental groups of the study after abrasive procedure. The same uppercase superscripts in columns indicate no significant differences between materials $(p>0.05)$. The same lowercase superscripts indicate no significant differences between treatments $(p>0.05)$.

\begin{tabular}{|c|c|c|c|c|c|c|}
\hline \multirow{2}{*}{ Material } & \multicolumn{2}{|c|}{ Control } & \multirow{2}{*}{$\% R \mathrm{a}$ increase } & \multicolumn{2}{|c|}{ Radiant heat } & \multirow{2}{*}{$\% R$ a increase } \\
\hline & Baseline surface & Abrasive surface & & Baseline surface & Abrasive surface & \\
\hline Ketac Fil Plus Aplicap & $0.161 \pm 0.019^{\mathrm{Aa}}$ & $0.211 \pm 0.025^{\mathrm{Ab}}$ & $23.7 \%$ & $0.169 \pm 0.015^{\mathrm{Aa}}$ & $0.205 \pm 0.020^{\mathrm{Ab}}$ & $17.6 \%$ \\
\hline IonoStar Molar & $0.213 \pm 0.022^{\mathrm{Ba}}$ & $0.236 \pm 0.026^{\mathrm{Bb}}$ & $9.7 \%$ & $0.216 \pm 0.027^{\mathrm{Ba}}$ & $0.227 \pm 0.023^{\mathrm{Ba}}$ & $4.8 \%$ \\
\hline
\end{tabular}

TABLE 4: Mean values and standard deviations of surface loss $(\mu \mathrm{m})$ of the experimental groups of the study after abrasive procedures. The same uppercase superscripts in columns indicate no significant differences between materials $(p>0.05)$. The same lowercase superscripts indicate no significant differences between treatments $(p>0.05)$.

\begin{tabular}{lccc}
\hline Material & Control & Radiant heat & $\%$ decrease \\
\hline Ketac Fil Plus Aplicap & $6.42 \pm 0.52^{\mathrm{Aa}}$ & $3.33 \pm 0.45^{\mathrm{Ab}}$ & $48.1 \%$ \\
IonoStar Molar & $2.05 \pm 0.21^{\mathrm{Ba}}$ & $0.41 \pm 0.09^{\mathrm{Bb}}$ & $80.0 \%$ \\
\hline
\end{tabular}

surfaces in all experimental groups $(p<0.05)$, except for radiant heat group of IM which did not present significant difference $(p>0.05)$. The increase in surface roughness after the abrasive procedure was lower in radiant heat groups (KF: 17.6\% and IM: $4.8 \%$ ) compared to control groups (KF: $23.7 \%$ and IM: $9.7 \%$ ) of both the tested GIC materials. Although the specimens of KF exhibited lower surface roughness than those of IM $(p<0.05)$, the specimens of IM showed greater resistance in abrasive procedures regarding surface roughness increase.

3.3. Surface Loss. Means and standard deviations $(\mu \mathrm{m})$ of surface loss of the abrasive surfaces of the specimens compared to the baseline surfaces of the experimental groups of the study are presented in Table 4 . Surface loss after the abrasive procedure was lower in radiant heat groups of both the tested GIC materials $(p<0.05)$. The decrease in surface loss after radiant heat treatment was $48.1 \%$ for KF and $80 \%$ for IM. The specimens of IM presented lower surface loss compared to those of KF $(p<0.05)$. Regression analysis between surface loss $(\mu \mathrm{m})$ and surface microhardness $(\mathrm{VHN})$ of the GIC materials is illustrated in Figure 4. Linear regression revealed that there is a low correlation between surface loss after abrasion and surface microhardness of the materials $\left(R^{2}=0.055\right)$. In particular, higher surface microhardness yields lower surface loss.

\section{Discussion}

According to the results of the present study the first null hypothesis $\left(\mathrm{H}_{0} 1\right)$ which stated that the radiant heat treatment did not influence the surface microhardness of the tested GIC materials, was rejected. This is in agreement with previous studies which investigated the effect of radiant heat treatments on surface hardness of GIC materials $[8,9,11,12$, 15]. Thermal energy providing by the LED light-curing unit increased surface hardness of the tested GIC materials by

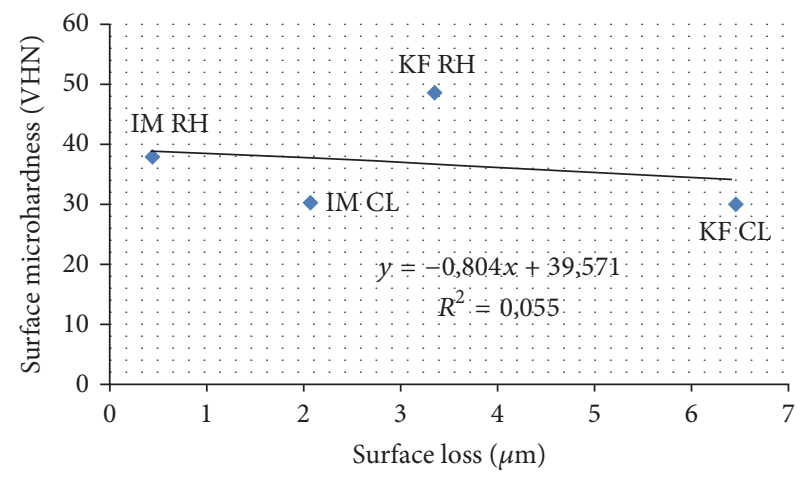

FIGURE 4: Regression analysis between surface microhardness (VHN) and surface loss after abrasion $(\mu \mathrm{m})$ of the experimental groups. KF CL: Ketac Fil Plus Aplicap control group, KF RH: Ketac Fil Plus Aplicap radiant heat group, IM CL: IonoStar Molar control group, and IM RH: IonoStar Molar radiant heat group.

thermocatalysis. More specifically, radiant heat transfer from a dental LED unit to the surface of the GIC specimens leads to increased ion mobility during the initial stage of setting, decreasing the viscosity of the material which further leads to enhanced reactivity between $\mathrm{Ca}$ ions of the glass particles (powder) and carboxylate groups of the polyalkenoic acids (liquid), and resulting in an improved and accelerated setting reaction [10]. Consequently, increase of surface hardness of GIC materials after the radiant heat treatment expresses the improved formation of polycarboxylate network due to thermocatalysis of the setting reaction attributed to the provided thermal energy [8].

The differences among different commercial products of conventional GIC materials in surface hardness may be attributed to discrepancies in their composition. In particular, the integrity of the interface between the glass particles and the matrix may improve the setting reaction and as a consequence the mechanical properties of GIC materials. Additionally, different size and shape of the glass particles dispersed in the matrix enable a more efficient packing and as a result a higher integrated glass particle-polyacid matrix leading to increased surface hardness of the material [8]. It has been reported that powder/liquid ratios and molecular weight, viscosity, and concentration of polyalkenoic acids included in the liquid component affect the mechanical properties of the GIC materials $[18,19]$. Nevertheless, in the present study the surface hardness of the two control groups of the tested GIC materials did not exhibit statistical differences. 
In contrast, the radiant heat groups of the tested GIC materials presented significant differences in surface hardness. KF exhibited $37.8 \%$ increase in surface hardness after the radiant heat treatment, whereas IM exhibited $19.7 \%$ increase. This difference between the tested GIC materials may be due to different composition and structure of the materials which influence their thermal properties. Gavic et al. [10] claimed that the effectiveness of radiant heat treatment to catalyze the maturation of GIC materials depends on their thermal properties such as thermal conductivity and thermal diffusivity. Previous studies reported that the thermal diffusivity for commercial conventional GIC materials ranged from $0.212 \times 10^{-2}$ to $0.303 \times 10^{-2} \mathrm{~cm}^{2} / \mathrm{sec}$ and the specific heat capacity from 1.011 to $1.368 \mathrm{~J} \mathrm{~K}^{-1} \mathrm{~g}^{-1}$, which are similar to human dentin [20].

As statistical analysis revealed, the second null hypothesis $\left(\mathrm{H}_{0} 2\right)$ of the study, which stated that the radiant heat treatment did not affect the surface roughness of the tested GIC materials after the abrasive procedure, was rejected. Moreover, the third null hypothesis $\left(\mathrm{H}_{0} 3\right)$ of the study, which stated that the radiant heat treatment did not influence the surface loss of the tested GIC materials after the abrasive procedure, was also rejected. This evidence could be explained by the increase in surface microhardness of GIC materials after the radiant heat treatments.

Surface roughness is a component of surface texture and it is quantified by the deviations in the direction of the normal vector of a real surface from its ideal form [21]. On the other hand, abrasive wear is defined as a progressive loss of a material caused by a solid surface or abrasive particles harder than the wearing solid surface [22]. Factors that may affect the extent of the abrasion to a material's surface are the size, shape, and type of the abrasive agent, the applied pressure, and the properties of the wearing surface [23]. As a matter of fact, increased surface hardness reduces wear loss and surface roughness of a material due to a greater resistance to abrasive mechanisms.

There are four different mechanisms of abrasion due to abrasive particles such as abrasive agents of toothpastes which were used in the current study: (a) microcutting, (b) microfracture, (c) pull-out of individual grains, and (d) accelerated fatigue by repeated deformations [24]. In the present investigation a three-body wear test was selected to evaluate the abrasion of GIC restoratives after toothbrushing. The three bodies of the test were the GIC surface, the toothpaste, and the toothbrush. At this type of tests the hard free-particles roll and slide between two solid surfaces leading to their wear [25]. Consequently, the abrasiveness of toothpastes is of great importance for the wear of the restorative materials during toothbrushing.

Surface roughness of the restorations and tooth tissues is crucial, as it plays a main role in the formation of dental biofilms and bacterial adhesion [26], which may lead to gingival inflammation [27]. Additionally, smooth surfaces of dental restorations not only result in optimal esthetics such as extrinsic staining but also provide acceptable health of soft tissues and marginal integrity of the restorative interface [28]. According to Bollen et al. [27] the critical mean surface roughness $(R \mathrm{a})$ value for bacterial colonization of restorative materials is considered to be $0.2 \mu \mathrm{m}$. Surface roughness, more than the critical roughness value, may cause significantly increased bacterial adhesion and dental plaque formation on the surface of restorative materials. In the present study, the mean $R$ a values of the GIC materials after the abrasion procedure slightly exceeded $0.2 \mu \mathrm{m}$. As a result, the surfaces of the GIC materials restorations maybe needed polishing after a sufficient time of daily dental hygiene in order to reduce their surface roughness below the critical value.

Dental GIC materials are heterogeneous materials with a biphasic nature and consist of nonreacted glass particles embedded in a polysalt resin matrix. The size, shape, concentration, and composition of the glass particles of the glass ionomer materials crucially affect the surface roughness and the resistance to wear. This may be the reason that in the present study the two tested GIC materials exhibited differences in these properties. Furthermore, during toothbrushing, the soft matrix phases are preferentially removed, leaving the harder, nonreacted glass particles to protrude from the surface and thus to determine surface roughness of the restorative [29].

In the present investigation linear regression analysis revealed a low negative correlation between surface hardness and surface loss after toothbrushing abrasion of the GIC materials $\left(R^{2}=0.055\right)$. This finding was expected because as surface microhardness of GIC increases the setting reaction improves and as a result the surface structure becomes more coherent leading to increased resistance to abrasive forces and reduced surface loss. However, this correlation is not strong and as a consequence the clinical significance of the results of the study and the effectiveness of the radiant heat treatment is necessary to be confirmed by clinical studies.

\section{Conclusions}

Within the limitations of this in vitro study the following statements can be concluded:

(i) The radiant heat treatment significantly increased the surface microhardness of both the tested conventional materials but in different extent.

(ii) Radiant heat groups of both the tested GIC materials presented lower surface roughness and surface loss after abrasive procedures compared to control groups.

(iii) A low negative correlation between surface hardness and surface loss after abrasive procedure was detected.

(iv) Between the tested GIC materials there were significant differences in their evaluated properties.

\section{Conflicts of Interest}

The authors declare that there are no conflicts of interest regarding the publication of this article. 


\section{Acknowledgments}

The experimental procedures of the study regarding the use of VSI microscope were performed at the Department of Basic Dental Sciences, Division of Dental Tissues Pathology and Therapeutics, School of Dentistry, Aristotle University of Thessaloniki, Greece.

\section{References}

[1] A. Wiegand, W. Buchalla, and T. Attin, "Review on fluoridereleasing restorative materials-fluoride release and uptake characteristics, antibacterial activity and influence on caries formation," Dental Materials, vol. 23, no. 3, pp. 343-362, 2007.

[2] D. Dionysopoulos, K.-K. Eugenia, H.-A. Maria, and K. Nikolaos, "Fluoride release and recharge abilities of contemporary fluoride-containing restorative materials and dental adhesives," Dental Materials Journal, vol. 32, no. 2, pp. 296-304, 2013.

[3] D. Dionysopoulos, K.-K. Eugenia, H.-A. Maria, and K. Nikolaos, "Fluoride release and recharge abilities of contemporary fluoride-containing restorative materials and dental adhesives," Oral Health \& Preventive Dentistry, vol. 14, pp. 371-380, 2016.

[4] J. W. Nicholson, "Adhesion of glass-ionomer cements to teeth: a review," International Journal of Adhesion and Adhesives, vol. 69, pp. 33-38, 2016.

[5] I. A. Rodriguez, C. A. Rozas Ferrara, F. Campos-Sanchez, M. Alaminos, J. U. Echevarría, and A. Campos, "An in vitro biocompatibility study of conventional and resin-modified glass ionomer cements," Journal of Adhesive Dentistry, vol. 15, no. 6, pp. 541-546, 2013.

[6] G. F. Molina, R. J. Cabral, I. Mazzola, L. Brain Lascano, and J. E. Frencken, "Biaxial flexural strength of high-viscosity glassionomer cements heat-cured with an LED lamp during setting," BioMed Research International, vol. 2013, Article ID 838460, 6 pages, 2013.

[7] J. W. Nicholson, "Chemistry of glass-ionomer cements: a review," Biomaterials, vol. 19, no. 6, pp. 485-494, 1998.

[8] T. O’Brien, F. Shoja-Assadi, S. C. Lea, F. J. T. Burke, and W. M. Palin, "Extrinsic energy sources affect hardness through depth during set of a glass-ionomer cement," Journal of Dentistry, vol. 38, no. 6, pp. 490-495, 2010.

[9] K. Tolidis, D. Dionysopoulos, P. Gerasimou, and T. Sfeikos, "Effect of radiant heat and ultrasound on fluoride release and surface hardness of glass ionomer cements," Journal of Applied Biomaterials and Functional Materials, vol. 14, no. 4, pp. e463e469, 2016.

[10] L. Gavic, K. Gorseta, D. Glavina, B. Czarnecka, and J. W. Nicholson, "Heat transfer properties and thermal cure of glassionomer dental cements," Journal of Materials Science: Materials in Medicine, vol. 26, no. 10, article no. 249, 2015.

[11] C. J. Kleverlaan, R. N. B. Van Duinen, and A. J. Feilzer, "Mechanical properties of glass ionomer cements affected by curing methods," Dental Materials, vol. 20, no. 1, pp. 45-50, 2004.

[12] D. Dionysopoulos, K. Tolidis, D. Strakas, P. Gerasimou, T. Sfeikos, and N. Gutknecht, "Effect of radiant heat on conventional glass ionomer cements during setting by using a blue light diode laser system (445 nm)," Lasers in Medical Science, vol. 32, no. 3, pp. 703-709, 2017.
[13] M. Dehurtevent, E. Deveaux, J. C. Hornez, L. Robberecht, N. Tabary, and F. Chai, "Influence of heat and ultrasonic treatments on the setting and maturation of a glass-ionomer cement," American Journal of Dentistry, vol. 28, no. 2, pp. 105-110, 2015.

[14] M. R. Towler, A. J. Bushby, R. W. Billington, and R. G. Hill, "A preliminary comparison of the mechanical properties of chemically cured and ultrasonically cured glass ionomer cements, using nano-indentation techniques," Biomaterials, vol. 22, no. 11, pp. 1401-1406, 2001.

[15] D. Dionysopoulos, K. Tolidis, P. Gerasimou, and T. Sfeikos, "Effect of three clinical curing treatments on fluoride release and surface hardness of glass-ionomer cements," The International Journal of Periodontics \& Restorative Dentistry, vol. 37, no. 4, pp. e197-e203, 2017.

[16] M. Shiozawa, H. Takahashi, N. Iwasaki, and M. Uo, "Effect of calcium chloride solution immersion on surface hardness of restorative glass ionomer cements," Dental Materials Journal, vol. 32, no. 5, pp. 828-833, 2013.

[17] M. U. S. Da Costa Soares, N. C. Araújo, B. C. D. Borges, W. Da Silva Sales, and A. P. V. Sobral, "Impact of remineralizing agents on enamel microhardness recovery after in-office tooth bleaching therapies," Acta Odontologica Scandinavica, vol. 71, no. 2, pp. 343-348, 2013.

[18] M. S. Baig and G. J. P. Fleming, "Conventional glass-ionomer materials: a review of the developments in glass powder, polyacid liquid and the strategies of reinforcement," Journal of Dentistry, vol. 43, no. 8, pp. 897-912, 2015.

[19] A. D. Wilder Jr., A. A. Boghosian, S. C. Bayne, H. O. Heymann, J. R. Sturdevant, and T. M. Roberson, "Effect of powder/liquid ratio on the clinical and laboratory performance of resinmodified glass-ionomers," Journal of Dentistry, vol. 26, no. 4, pp. 369-377, 1998.

[20] T. Inoue, M. Saitoh, and M. Nishiyama, "Thermal properties of glass ionomer cement.", The Journal of Nihon University School of Dentistry, vol. 35, no. 4, pp. 252-257, 1993.

[21] D. Whitehouse, Surfaces and their Measurement, ButterworthHeinemann, Massachusetts, Mass, USA, 2012.

[22] X. Jia and R. Ling, "Two-body free-abrasive wear of polyethylene, nylon1010, expoxy and polyurethane coatings," Tribology International, vol. 40, no. 8, pp. 1276-1283, 2007.

[23] Ö. Kanik, L. S. Turkun, and W. Dasch, "In vitro abrasion of resin-coated highly viscous glass ionomer cements: a confocal laser scanning microscopy study," Clinical Oral Investigations, vol. 21, no. 3, pp. 821-829, 2017.

[24] V. Jankauskas and R. Skirkus, "Steel abrasive wear forecasting by wearing surfaces microgeometric parameters," Mechanika, vol. 19, no. 4, pp. 486-490, 2013.

[25] R. DeLong, "Intra-oral restorative materials wear: rethinking the current approaches: How to measure wear," Dental Materials, vol. 22, no. 8, pp. 702-711, 2006.

[26] N. Hosoya, K. Honda, F. Iino, and T. Arai, "Changes in enamel surface roughness and adhesion of Streptococcus mutans to enamel after vital bleaching," Journal of Dentistry, vol. 31, no. 8, pp. 543-548, 2003.

[27] C. M. Bollen, P. Lambrechts, and M. Quirynen, "Comparison of surface roughness of oral hard materials to the threshold surface roughness for bacterial plaque retention: a review of the literature," Dental Materials, vol. 13, no. 4, pp. 258-269, 1997. 
[28] V. Cavalli, C. A. G. Arrais, M. Giannini, and G. M. B. Ambrosano, "High-concentrated carbamide peroxide bleaching agents effects on enamel surface," Journal of Oral Rehabilitation, vol. 31, no. 2, pp. 155-159, 2004.

[29] D. Dionysopoulos, E. Koliniotou-Koumpia, and P. Dionysopoulos, "Surface finish produced on five aesthetic restorative materials by new polishing systems," Balkan Journal of Stomatology, vol. 16, pp. 27-33, 2012. 

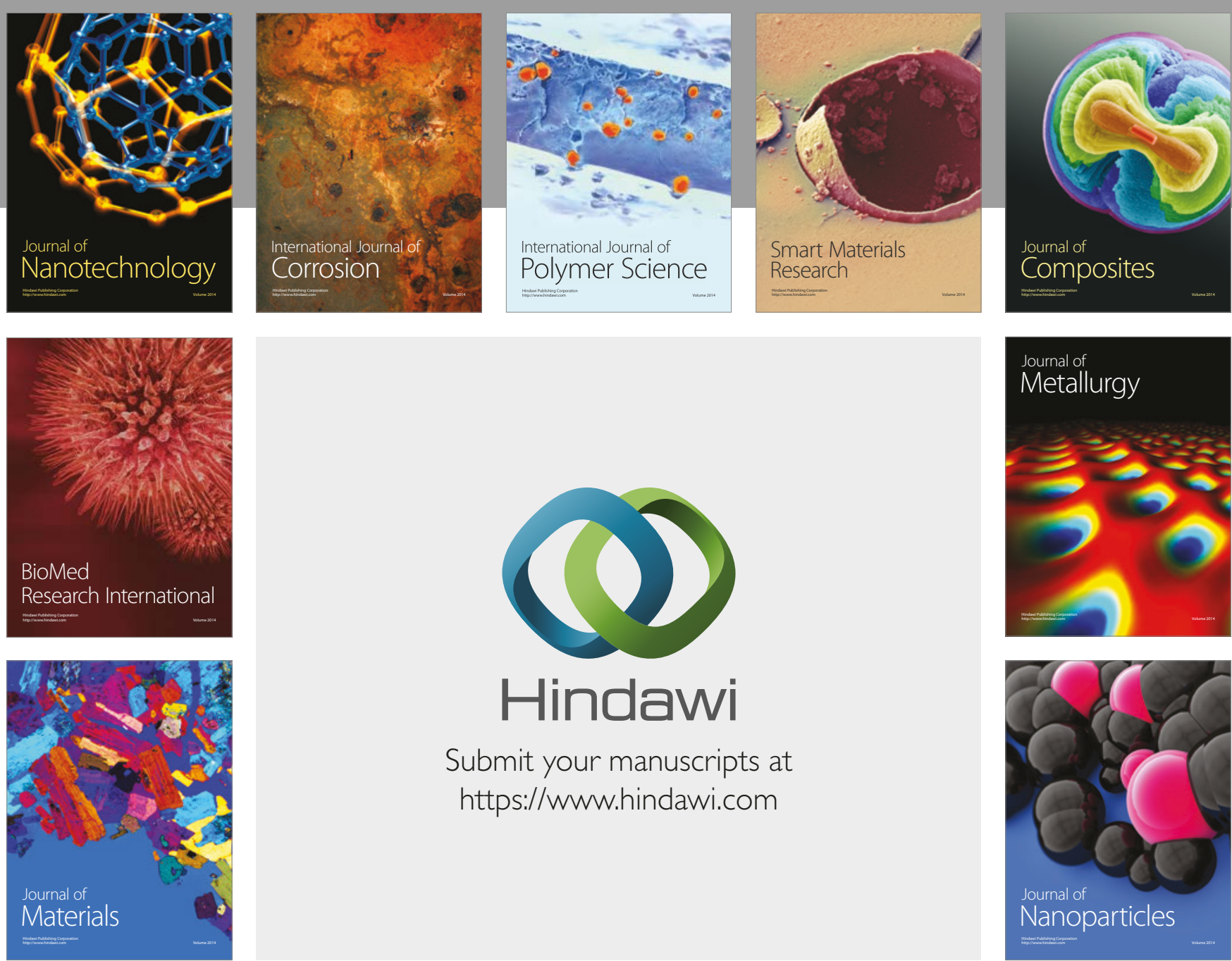

\section{Hindawi}

Submit your manuscripts at

https://www.hindawi.com
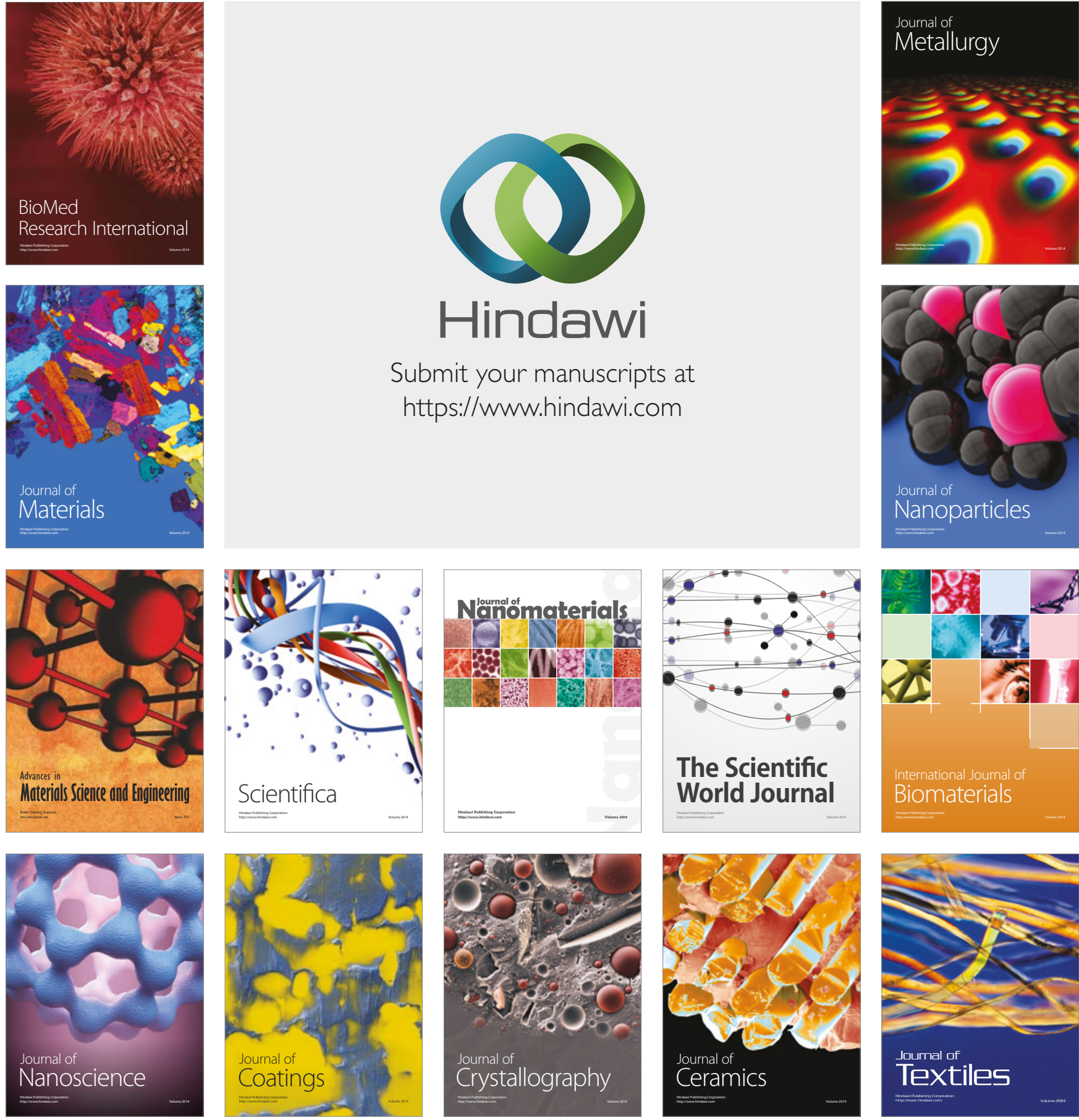

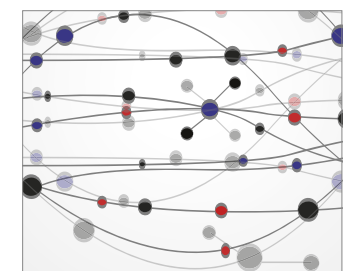

The Scientific World Journal
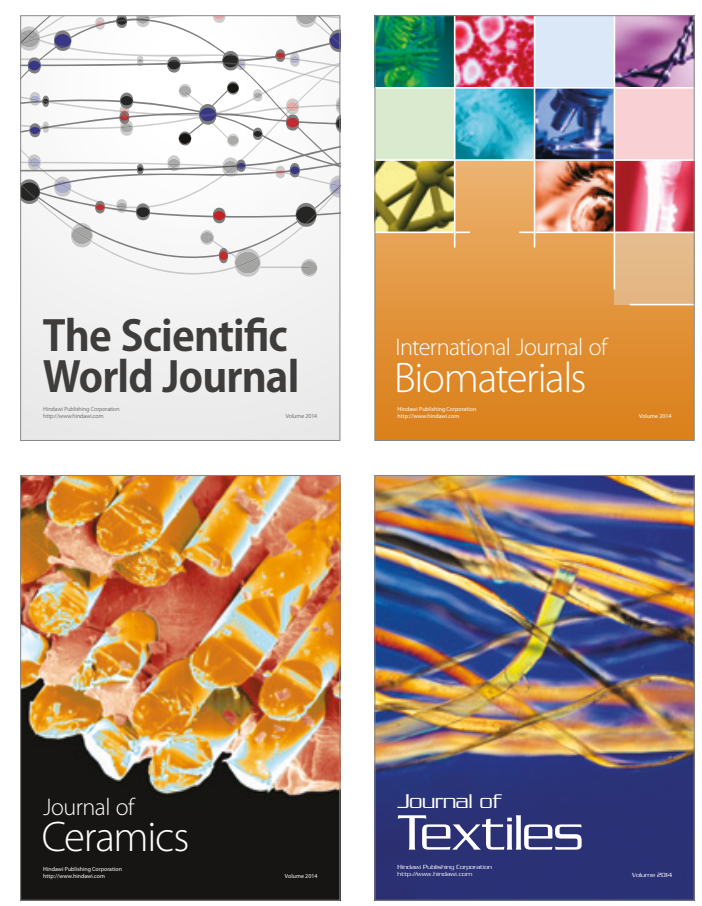